\title{
La ética profesional de los periodistas frente a los gobiernos y políticos: Percepciones de los profesionales y ciudadanos en España
}

\section{The professional ethics of journalists in front of governments and politicians: Perceptions of professionals and citizens in Spain}

Marcel Mauri-Rios. Universitat Pompeu Fabra. España.

marcel.mauri@upf.edu

$[\underline{\mathrm{CV}}]$ (1) G

Amparo López-Meri. Universidad Jaume I. España.

meri@uji.es

$[\mathrm{CV}]$ C $\mathrm{C}$

Cristina Perales-García. Universitat Pompeu Fabra. España.

cristina.perales@upf.edu

$[\mathrm{CV}]$ (1) $\mathrm{G}$

Este artículo es producto del proyecto de investigación Accountability y Culturas Periodísticas en España. Impacto y propuesta de buenas prácticas en los medios de comunicación españoles Ref. CSO2015-66404-P, financiado por el Ministerio de Economía y Competitividad (MINECO/FEDER, UE). Enero 2016-junio 2020

Cómo citar este artículo / Referencia normalizada

Mauri-Rios, M., López-Meri, A. y Perales-García, C. (2020). La ética profesional de los periodistas frente a los gobiernos y políticos: Percepciones de los profesionales y ciudadanos en España. Revista Latina de Comunicación Social, (77), 295-308.

https://www.doi.org/10.4185/RLCS-2020-1459

\section{RESUMEN}

Introducción: En el presente trabajo se analizan las presiones que desde la política se han ejercido o intentado ejercer sobre el periodismo. Metodología: A partir de la combinación de metodologías cualitativas, como los grupos de discusión con ciudadanos, y cuantitativas, como encuestas a las profesionales, se analiza cómo esta influencia de la política sobre los periodistas puede llegar a limitar los instrumentos de rendición de cuentas de los que disponen los medios de comunicación. Resultados: los resultados de esta investigación ponen en evidencia que periodistas y ciudadanos comparten la percepción que las influencias políticas son uno de los principales supuestos que afectan al desarrollo de un buen periodismo. Discusión/conclusiones: Pese a que los periodistas reconocen las presiones políticas y gubernamentales, el estudio concluye que no ceden ante ellas ni se sienten responsables ante partidos o gobiernos.

PALABRAS CLAVE: ética; autorregulación; periodismo; España; política; deontología; códigos éticos, rendición de cuentas. 


\begin{abstract}
Introduction: This paper analyses the pressures that journalism has exerted or attempted to exert from politics. Methodology: The study uses a combination of qualitative methodologies, such as focus groups discussion, and quantitative ones, such as surveys of journalists; both methodologies allows to know how politics influence journalists and how it can limit media instruments of accountability. Results: this study presents the results of an investigation that shows that journalists and citizens share the perception that political influence is one of the main assumptions that affect the development of good journalism. Discussion/conclusion: Although journalists recognize political and government pressures, the study concludes that they do not give in or feel responsible to political parties or governments.
\end{abstract}

KEYWORDS: ethics; self-regulation; journalism; Spain; politics; deontology; codes of ethics; accountability.

\title{
CONTENIDOS
}

1. Introducción. 2. Marco teórico. 3. Metodología. 4. Resultados. 5. Discusión y conclusiones. 6. Bibliografía.

\section{Introducción}

La relación entre poder político y periodismo es tan antigua como lo es la propia profesión periodística. Ya en el siglo XVIII, Edmund Burke formulaba por primera vez el concepto de "cuarto poder" (Guillamet, 2003), en referencia al rol que ejercen los medios de comunicación en una democracia de vigilar a los otros poderes de un estado. De hecho, uno de los elementos que permite calibrar la salud democrática de una sociedad es la independencia que los medios mantienen respecto al poder político (Alsius, 2010, p. 138), un punto esencial para que los periodistas puedan ejercer esta función democratizadora. Al fin y al cabo, la ciudadanía precisa de información constante, veraz e independiente para poder desarrollarse en una sociedad libre (Kovach y Rosenstiel, 2001). Pero esta independencia de los medios de comunicación frente a gobiernos y políticos es percibida de formas muy distintas según los países o las tradiciones periodísticas (Hallin y Mancini, 2004).

El presente artículo presenta los resultados de una investigación que analiza las percepciones que periodistas y ciudadanos españoles tienen sobre cómo el poder político influye sobre el comportamiento de los medios de comunicación y hasta qué punto esta voluntad de control político limita la capacidad de los medios de rendir cuentas a la ciudadanía. Esta investigación introduce de forma inédita la percepción ciudadana - una aportación original que contribuye a complementar la mirada de los profesionales de la comunicación- para abordar la percepción que estos dos grupos tienen sobre cómo la influencia de la política condiciona las prácticas periodísticas. En concreto, los objetivos de este estudios son a) identificar hasta qué punto tanto periodistas como ciudadanos perciben que las presiones políticas son un problema para el periodismo en España; b) comprobar cuál es la respuesta que desde estos dos colectivos se considera que deben dar los medios de comunicación ante la posible injerencia política; y, c) identificar las principales barreras que en el contexto español dificultan la rendición de cuentas de los periodistas debido a la injerencia del poder político.

En este sentido, se plantean diversas preguntas de investigación:

PI1. ¿Cómo afectan las presiones gubernamentales y políticas al ejercicio del periodismo?

PI2. ¿Cómo son percibidas estas presiones tanto por periodistas como por la ciudadanía?

PI3. ¿Cómo reaccionan periodistas y ciudadanos ante estas presiones?

PI4. ¿Qué papel juega la influencia del poder político a la hora de limitar la rendición de cuentas de los periodistas y medios de comunicación? 


\section{Marco teórico}

A través de su poder para fijar la agenda mediática y política, los medios de comunicación son percibidos como una fuerza central en las democracias modernas (Green y Stubager, 2010). El periodismo ejerce una función fundamental en los regímenes liberales ya que una ciudadanía informada y con conocimiento político es clave para la construcción de sociedades libres (CaseroRipollés, 2012). Garantizar el derecho a la información de la ciudadanía es una misión fundamental de medios y profesionales de la comunicación (Mauri-Ríos, Marcos-García y Zuberogoitia-Espilla, 2020) Para cumplir esta función democratizadora, los periodistas deben poder informar con objetividad y distanciarse lo máximo posible de cualquier tipo de influencias y presiones. Estas injerencias, ya sean de tipo político o económico, preocupan a los periodistas en la medida que limitan su independencia y capacidad de poder ejercer un periodismo libre (Alsius y Salgado, 2010; Fengler et al., 2015).

Estudios recientes, basados en la campaña electoral y el mandato de Donald Trump o en el referéndum sobre el Brexit en el Reino Unido, muestran cómo esta voluntad de interferencia política se ha agudizado en los últimos años (Graber y Dunaway, 2017; McNair, 2018). Pero también ocurre el fenómeno contrario: distintos autores (Mazzoleni y Schulz, 1999; Meyer, 2002; Strömbäck, 2011) han constatado cómo los políticos dependen cada vez más de los medios de comunicación, y cómo estos medios han ido colonizando la política hasta el punto de que no se toman decisiones políticas sin pensar en la forma en que serán expuestas en los medios, debido a la capacidad de los medios de masas de influir en la construcción de la agenda política (Green y Stubager, 2010). Otros estudios constatan como la aparición de las redes sociales, como Facebook, pero particularmente Twitter, todavía han añadido más relación y capacidad de presión de la política al periodismo, y viceversa (Parmelee, p. 2013)

Esta relación o influencia mutua que los medios reciben o ejercen sobre la política está condicionada por los principios y valores profesionales que rigen el periodismo (Alsius, 2010). Los periodistas y los medios deben regirse por la doble necesidad de garantizar que se cumple el derecho a la información y expresión de la ciudadanía sin olvidar el seguimiento de unos principios y responsabilidades que deberían ser inherentes a la propia profesión periodística. (Rodríguez, López, Merino y Mauri, 2017).

Con el fin de trabajar en aras del interés público y dar cumplimiento a los valores básicos del periodismo -que autores como Alsius han clasificado en cuatro principios como la verdad, la justícia, la responsabilidad y la libertad (1999)-, los periodistas deben seguir una ética profesional, lo que Kovach y Rosenstiel llaman una "brújula moral" (2001, p. 181). Esta ética profesional es la base para realizar una comunicación orientada a la excelencia y la calidad informativa (Mauri y Ramon, 2015). La ética profesional debe anclarse en criterios de actuación que permitan dirimir el grado de cumplimiento de una correcta praxis profesional. Dichas pautas han sido recogidas tradicionalmente en los códigos deontológicos. Más recientemente, también se concretan a través de otros instrumentos de rendición de cuentas que agilizan la interacción entre medios y ciudadanos, y que pueden contribuir a esta tarea de exigir responsabilidad a los periodistas (Suárez, Rodríguez, Mauri, López, 2017, p. 322). Según la definición de Mauri y Ramon (2015, p. 381), la rendición de cuentas en periodismo implica que los medios apliquen la transparencia informativa, desarrollen instrumentos de autorregulación y fomenten la participación de los usuarios. Se debe tener en cuenta que rendir cuentas en un entorno mediático es un elemento esencial para garantizar la pluralidad e independencia de los medios (Bertran, 2010). 
Los principios éticos comúnmente aceptados por la profesión periodística también hacen referencia a esta relación entre los periodistas y el poder político. A partir de los estudios de análisis y compilación de códigos y documentos con normativa deontológica realizados por Aznar (1999), Pérez-Fuentes (2004) y Alsius (2010), en el ámbito español, o de Noordenstreng y Hannikainen (1984), Weaver y Wilhoit (1986), Bertrand (2000) y Fengler y RussMohl (2008), en el ámbito europeo e internacional, se observa como estos condicionantes políticos son motivo de preocupación para la profesión periodística. Alsius $(1999,2010)$ clasifica los principios de la ética periodística de los principales códigos españoles e internacionales en cuatro apartados: principios de verdad, justicia, responsabilidad y libertad; y sitúa en este último ámbito lo referente al control que el poder político puede ejercer sobre el periodismo. Control que de ejercerse limitaría claramente este principio periodístico de la libertad y pondría en riesgo la capacidad de los medios de ejercer su función con independencia (Alsius, 2010).

Otras investigaciones recientes sostienen que los condicionantes políticos que marcan la relación entre periodistas y poder político se han ido agudizando (Casero y López, 2016; Hallin y Mancini, 2004; Almirón, Narberhaus y Mauri, 2016; Sjøvaag, 2020). Algunos estudios indican que en la cultura periodística pluralista-polarizada o mediterránea donde se inscribe el periodismo español (Rodríguez-Martínez et al., 2017) a diferencia de lo que puede ocurrir en el norte de Europa o en los países anglosajones, algunas corporaciones mediáticas aprovechan su capacidad de influencia y relación con el poder para recibir favores políticos (Van Dalen, 2012, p. 482). La investigación sobre esta influencia del poder político sobre el periodismo en este tipo de culturas periodísticas menos profesionalizadas e independientes es clave en la medida que esta relación puede llegar a condicionar los contenidos que ofrecen los medios de comunicación (Tandoc, 2018; Maheshwari y Sparks, C., 2018).

La mayoría de la literatura existente sobre la influencia gubernamental y política sobre los medios aborda esta relación consustancial entre el poder político y los medios de comunicación desde la mirada de los propios políticos y periodistas. Esta investigación aporta una mirada innovadora ya que no es frecuente incluir la percepción de la ciudadanía en este tipo de estudios.

\section{Metodología}

Esta investigación se ha desarrollado a partir de la combinación de diferentes metodologías cuantitativas y cualitativas. Concretamente, para indagar en las percepciones de los periodistas se han realizado encuestas y entrevistas en profundidad, mientras que las impresiones de la ciudadanía se abordan a través de grupos de discusión. Todas estas técnicas se han desplegado en seis territorios españoles: Andalucía, Cataluña, Comunidad Valenciana, Galicia, Madrid y País Vasco.

Respecto a la técnica cuantitativa de la encuesta, se diseñó un cuestionario online con 29 preguntas sobre los condicionantes que afectan a la práctica informativa, las obligaciones de los medios, su relación con la audiencia, la responsabilidad de los periodistas ante varios agentes y la eficacia de los instrumentos de rendición de cuentas. El cuestionario, que combina preguntas dicotómicas, de opción múltiple y en forma de escala de valoración (Wimmer y Dominick, 2011), se administró a través de la plataforma SurveyMonkey (entre octubre de 2017 y enero de 2018). Para conseguir más participación, entidades como la Federación de Asociaciones de Periodistas de España (FAPE), el Col-legi de Periodistes de Catalunya (CPC) o la Asociación de la Prensa de Madrid (APM) contribuyeron a difundir la encuesta a través de múltiples canales. Los datos recopilados se han analizado empleando el software especializado IBM Statistical Package for the Social Sciences (SPSS). 
De acuerdo con los criterios establecidos por Weischenberg, Malik y Scholl (2006, p. 227), posteriormente usados por el proyecto europeo Media Accountability and Transparency in Europe (MediaAcT, EU SSH-2009-5.1.1), los encuestados debían ejercer tareas periodísticas en un medio de comunicación periodístico (excluidos profesionales con tareas de relaciones públicas), y al menos la mitad de sus ingresos debían proceder de su profesión como periodistas (se incluye al freelance si el 50 por ciento de sus ingresos deriva de actividades periodísticas). En España no existe ningún censo oficial de periodistas (Fengler et al., 2015; Rodríguez, Mauri y Fedele, 2017). Ante esta limitación, combinando criterios como el número de periodistas afiliados a asociaciones profesionales y los diferentes tipos de medios, estudios previos han determinado que la población estimada de periodistas en España es de 25.000, y que para abordar con garantías el caso español sería válida una muestra de 100 participantes (Eberwein et al., 2014, p. 72).

En la investigación que nos ocupa, se han obtenido 228 respuestas $(\mathrm{N}=228)$. Respecto a los participantes, predominan las mujeres (52.2\%). La mayoría se concentra en el rango de edad de 35 a 44 años (31.6\%), seguido de las franjas de 25 a 34 años $(25.4 \%)$ y de 45 a 54 años (23.2\%). Cuatro de cada diez afirman tener más de 20 años de experiencia periodística (42.5\%). Trabajan mayoritariamente en la prensa escrita $(18.4 \%)$ y la radio pública $(18 \%)$, mientras que el resto de medios registran porcentajes inferiores al 10\%. La mayoría cuenta con formación universitaria en periodismo $(71.1 \%)$, y un porcentaje elevado confiesa no pertenecer a ningún sindicato de periodistas (81.6\%), aunque la mitad admite formar parte de alguna asociación o colegio profesional (53.1\%).

Por otro lado, se han realizado seis focus groups, uno en cada territorio incluido en la muestra. Esta técnica cualitativa consiste en reunir a un grupo de entre 6 y 8 personas desconocidas entre ellas para debatir sobre un tema concreto, bajo la dirección de un moderador que introduce preguntas previamente definidas. Los participantes en el grupo son influidos e influyen en el resto de participantes, interaccionando y compartiendo opiniones y experiencias. Al respecto, han participado un total de 38 personas, 22 mujeres y 16 hombres, que han expresado sus opiniones sobre la ética en el periodismo actual, los instrumentos para garantizar la ética de los medios y las actitudes de los periodistas desde el punto de vista ético. Todos los grupos de discusión se desarrollaron en mes y medio (entre el 12 de abril y el 31 de mayo de 2018). El 42\% de los participantes tiene una edad media y el resto se reparte casi a partes iguales entre los menores de 30 años y los mayores de 60. Los que tienen una formación más alta son doctores o graduados, algunos en el ámbito de la comunicación audiovisual y el periodismo. Las personas con formación media o baja, en su mayoría, se dedican a tareas de administración o comerciales.

\section{Resultados}

\subsection{Las percepciones de los periodistas y expertos}

Cuando se pregunta a los periodistas sobre qué supuestos afectan más directamente al ejercicio de su profesión, en una escala del 0 a 10, los encuestados sitúan las presiones gubernamentales y políticas en quinta y séptima posición, con 7,62 y 7,54 puntos, respectivamente (gráfico 1), por detrás del salario percibido, la politización de los medios, las presiones económicas, la dependencia de fuentes institucionales y la influencia de la audiencia. Como se aprecia en el gráfico, mayoritariamente, estos otros factores también guardan relación con el poder político.

Además, los resultados de las encuestas muestran que los años de experiencia resultan indispensables para actuar contra la presión en la profesión. Los participantes de mayor edad admiten menos presión que los de menor edad. Sin embargo, todos manifiestan abiertamente la existencia de tales presiones y las sitúan con un valor superior al 7,5 en una escala del 0 al 10, donde 0 no les afecta en absoluto y 
10 indica una afectación total. Para los grupos de edad comprendidos entre los 19 y 24 años, las presiones gubernamentales reciben 8 puntos sobre $10 \mathrm{y}$ las presiones políticas 7,78. La franja de edad que menos puntuación concede a estas influencias es la de 45 a 54 años, aunque la calificación no dista en exceso de la expresada por los jóvenes, pues la sitúan en 7,19 y 7,25, respectivamente.

Con respecto al tratamiento informativo, cuando deben referirse a gobiernos e instituciones, los encuestados confiesan que ofrecen más información sobre el poder ejecutivo que sobre los representantes políticos de la oposición en un 57\% de los casos. Sin embargo, admiten no publicar sistemáticamente informaciones oficiales un $85,5 \%$ de las veces.

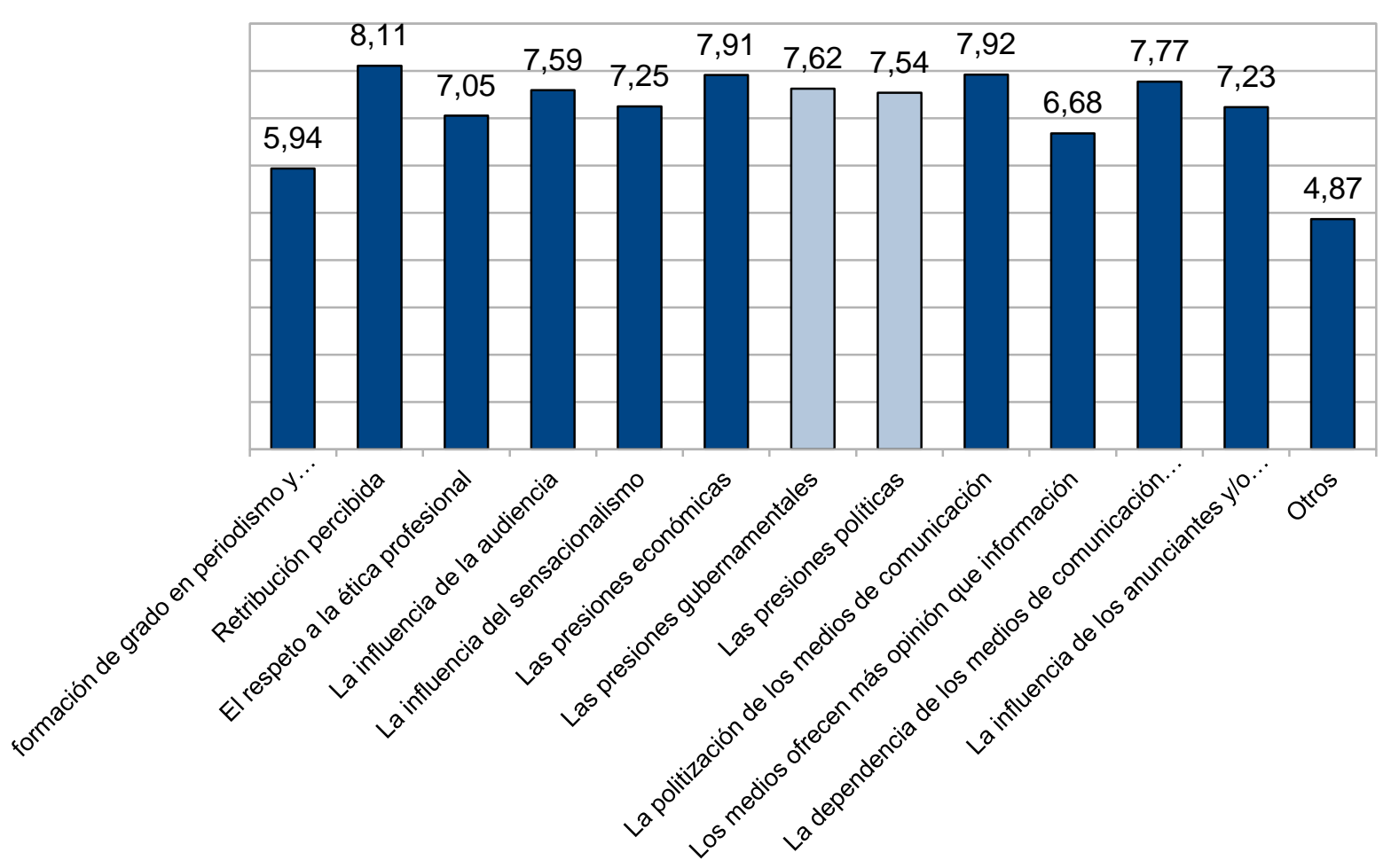

Gráfico 1: supuestos que afectan a la situación general del periodismo.

Fuente: elaboración propia a partir de los datos de la encuesta.

A pesar de estas presiones, un 90,4\% de los periodistas encuestados confiesa que no entrevista a los cargos del gobierno cuando estos lo solicitan, y solo admite este hábito un 9,6\% de los profesionales. De forma relacionada, los informantes indican, en un $82,9 \%$ de los supuestos, que dotan de mayor protagonismo a fuentes no institucionales, aunque admiten que en caso de emergencias publican las recomendaciones oficiales en un $91,2 \%$ de los casos.

En cuanto a la atención que los encuestados prestan a las indicaciones del Gobierno español para orientar o embargar una información importante que afecte la seguridad del Estado, las respuestas están muy equilibradas: el 51,2\% dice no aceptar tales indicaciones, frente al 48,7\% que las admite subrayando la importancia de preservar la seguridad nacional.

Cuando se pregunta a los periodistas ante quién se sienten responsables, las respuestas varían en función de sus años de experiencia (ver tabla 1). A menor veteranía en el ejercicio de la profesión, más se sienten responsables ante su propia conciencia (con un valor de media de 9,75 en una escala de 0 a 10, donde 0 no dota de ningún valor y donde 10 supone la atención máxima). Por otro lado, 
los encuestados con un máximo de 5 años de experiencia, sitúan a su superior directo como la persona a la que deben rendir cuentas (con una puntuación media de 8,21). Cuando cuentan con 15 años de antigüedad en la profesión, valoran con más nota (un 9) la obligación de rendir cuentas a sus fuentes informativas.

Tabla 1. Ante quién o qué se sienten responsables los periodistas consultados.

\begin{tabular}{|c|c|c|c|c|c|c|c|c|c|c|c|c|c|c|c|}
\hline & & $\begin{array}{c}\mathrm{Mi} \\
\text { conciencia }\end{array}$ & $\begin{array}{c}\text { Mi superior } \\
\text { directo }\end{array}$ & $\begin{array}{c}\text { Mis } \\
\text { compañeros } \\
\text { de redacción }\end{array}$ & $\begin{array}{c}\text { Las normas } \\
\text { éticas de la } \\
\text { profesión }\end{array}$ & Mis fuentes & $\begin{array}{c}\mathrm{La} \\
\text { audiencia/ } \\
\text { público }\end{array}$ & $\begin{array}{c}\text { Nuestros } \\
\text { anunciantes }\end{array}$ & $\begin{array}{c}\text { El gobierno } \\
\text { del Estado } \\
\text { español }\end{array}$ & $\begin{array}{c}\text { El gobierno } \\
\text { de la } \\
\text { Comunidad } \\
\text { Autónoma } \\
\text { donde } \\
\text { trabajo }\end{array}$ & $\begin{array}{l}\text { Partidos } \\
\text { políticos }\end{array}$ & $\begin{array}{c}\text { Valores } \\
\text { democrático } \\
\mathrm{s}\end{array}$ & \begin{tabular}{|c|} 
Autoridades \\
religiosas/ \\
grupos \\
religiosos
\end{tabular} & $\begin{array}{c}\text { Dios o mis } \\
\text { valores } \\
\text { religiosos }\end{array}$ & Otros \\
\hline & & Media & Media & Media & Media & Media & Media & Media & Media & Media & Media & Media & Media & Media & Media \\
\hline \multirow[t]{6}{*}{$\begin{array}{l}\text { Edad por } \\
\text { grupos }\end{array}$} & $19-24$ & 8,67 & 6,44 & 7 & 8,11 & 7,44 & 7,67 & 1,78 & 1,55 & 4 & 2,89 & 8,22 & 0,22 & 0,22 & $0^{*}$ \\
\hline & $25-34$ & 9,62 & 8,21 & 7,64 & 9,14 & 9,21 & 8,52 & 3,43 & 1,75 & 2,88 & 2,09 & 8,21 & 1,14 & 0,72 & 3,5 \\
\hline & 34-44 & 9,32 & 7,5 & 7,76 & 9 & 8,85 & 8,68 & 3,71 & 2,38 & 3 & 2,46 & 8,49 & 1,63 & 0,78 & 0,63 \\
\hline & 45-54 & 9,42 & 7,02 & 7,47 & 9,21 & 9,34 & 8,96 & 4,77 & 2,06 & 2,15 & 1,75 & 8,77 & 1,49 & 1,87 & 4,38 \\
\hline & 55-64 & 9,38 & 6,06 & 7,12 & 8,65 & 8,38 & 8,85 & 6,5 & 1,97 & 2,5 & 1,79 & 9,06 & 1,38 & 1,35 & 0,5 \\
\hline & $65+$ & $9,5^{*}$ & 9* & 9* & $9,5^{*}$ & $9,5^{*}$ & 9* & $4^{*}$ & $2,5^{*}$ & $2,5^{*}$ & $1 *$ & 9* & 0* & 0* & $*$ \\
\hline
\end{tabular}

Fuente: elaboración propia.

Su percepción sobre la rendición de cuentas también varía en función del tipo de medio informativo para el que trabajan. En primera instancia, la gran mayoría coincide en que se deben a su propia conciencia, supuesto valorando con un 10 en el caso de los trabajadores de semanarios o con valores superiores a 9 en el caso de los periodistas freelance, de agencia de noticias, radios privadas y públicas, diarios y revistas no diarias. En segunda posición, los trabajadores de agencias informativas sitúan a su superior directo; los periodistas de la radio privada sitúan a sus compañeros de la redacción; y los redactores de semanarios escogen las normas éticas y las fuentes informativas. En cambio, no prestan tanta atención a la necesidad de dar explicaciones a la audiencia, un aspecto que contrasta con la opinión de la ciudadanía que se analiza en el siguiente apartado.

En líneas generales, se observa que los periodistas no rinden cuentas ante los partidos políticos $(2,11)$, ni tampoco ante los gobiernos de sus respectivas comunidades $(2,73)$ ni ante el gobierno español $(2,05)$.

\subsection{Las percepciones de la ciudadanía}

A partir de los focus groups o grupos de discusión con ciudadanos, se aprecia que la influencia del poder político es uno de los factores que genera desconfianza y contribuye a la visión negativa del periodismo entre el público. Según los ciudadanos participantes, esta influencia afecta a la objetividad e independencia del periodista, incluso menoscaba la libertad de expresión; también perjudica la objetividad, porque los medios de comunicación, según aseguran los participantes, siguen una línea ideológica que responde a intereses económicos y políticos. Cuando esta línea ideológica entra en conflicto con la ética del periodista, se pone en riesgo su autonomía e independencia. También se menoscaba la libertad de expresión, porque el periodismo actual es más homogéneo ideológicamente, por la influencia del neoliberalismo, y esta falta de diversidad, según argumentan, resta efectividad a la libertad de expresión.

No obstante, para los ciudadanos participantes en los grupos de discusión el problema no es tanto la línea ideológica del medio como su vinculación a un partido político concreto. Así, los participantes 
diferencian entre la perspectiva ideológica del medio, legítima en un contexto de pluralidad democrática, y la influencia directa de un partido sobre el medio, entendida como una relación de dependencia que difícilmente permitirá asumir la visión crítica que se espera del periodismo: "la línea editorial de un periódico no debería encajar totalmente en la ideología de un partido, porque eso ya es propaganda" (mujer, focus group $\mathrm{n}^{\circ} 4$ ).

Por otro lado, la ciudadanía también percibe una vinculación directa entre intereses políticos y rédito económico. Algunos participantes comentan que la compra de un medio por parte de una gran corporación puede cambiar su postura ideológica en un tema concreto. Lo mismo sucede en los medios públicos cuando cambia el partido político del gobierno.

La percepción general es que los partidos en el poder controlan a ciertos medios ideológicamente, revisando las noticias antes de su difusión, y en el caso de medios públicos, a través de la elección de sus directivos. "Cuando el presidente del Gobierno Mariano Rajoy estaba sentado en el banquillo, no se emitió en el canal 24 horas" de Televisión Española, dice una participante, a la que se suman otros testimonios: "la libertad de expresión no existe, porque el directivo del informativo es una persona que está enchufada por el partido que gobierna ahora mismo en España." (mujer, focus group $\mathrm{n}^{\circ} 3$ ). "Tengo amigos que se dedican al periodismo en Madrid y tienen las manos atadas. Primero controlan los políticos. Antes de lanzar la noticia, la leen y si ven que va por donde ellos quieren, la noticia pasa, pero si no, no" (mujer, focus group no 5).

En general, consideran que la capacidad de influencia, además, se aprecia en el interés de los propios políticos por gestionar los medios y controlar los discursos. Como dice algún participante, personas afines, incluso pagadas por algunos perfiles políticos, se dedican a participar en tertulias para respaldar ciertas ideas.

La percepción global de los participantes en los grupos de discusión es negativa en relación con la cobertura de informaciones que afectan al poder político. Según se desprende de sus comentarios, las noticias de carácter político suelen moverse entre la evasión, la tergiversación o la condescendencia si se trata de ideologías cercanas a las del medio emisor. Respecto a la evasión, aseguran que se concreta en prácticas como obviar datos, esconder fuentes o narraciones, retrasar la publicación, restar importancia a los hechos o entorpecer su visibilización, como ocurre con la corrección de errores, que suele ir en la última página. La tergiversación se produce por la manipulación en la exposición o el tratamiento de los datos.

Al respecto, la ciudadanía habla de favoritismo hacia determinados políticos y de noticias tendenciosas, donde se mezcla la información y la opinión. Los medios "informan en un porcentaje y deforman en otro porcentaje", añade un ciudadano. "Por un lado, tenemos exceso de información y, por otro lado, tenemos una manipulación burda en función de los intereses del que emite esa información", agrega uno de los participantes. En cambio, si el partido afectado tiene una ideología afín a la del medio, la actitud del medio es condescendiente, las preguntas del periodista resultan poco incisivas y la noticia resultante, poco crítica. Algunos participantes creen que no se investiga lo suficiente: "Echo de menos una prensa mucho más incisiva. Encuentro que los periodistas son mucho más condescendientes con los personajes públicos, y con los políticos en concreto, sobre todo con los que gobiernan. (...) [los periodistas] se tragan las mentiras y se quedan tan anchos; y después no hay una crítica, no ponen en evidencia [a los políticos].” (mujer, focus group $\mathrm{n}^{\mathrm{o}} 1$ ). “El político sale y dice lo que le parece? Pues muy bien, pero después habrá un periodista que, como buen analista del discurso, tiene que ser crítico" (mujer, focus group $\mathrm{n}^{\circ} 2$ ) 
No obstante, algunos testimonios consideran que la dificultad no escriba en la falta de espíritu crítico del periodista, sino en otros factores que condicionan su trabajo, como la línea editorial, la falta de cultura democrática entre los políticos, que suelen atender a medios de ideología afín o no responden a las preguntas de los periodistas, o el miedo ante leyes cada vez más restrictivas. La ciudadanía también apunta que muchas veces no se aporta la suficiente diversidad de posturas en torno a las cuestiones políticas.

Además, la ciudadanía denuncia que los hechos parecen convertirse en noticia si permiten criticar al partido contrario a la ideología del medio. Algunos partidos reciben más atención negativa que el resto, respondiendo a los intereses de los medios.

La mayoría de los participantes en los focus group entienden que los periodistas, en primer lugar, deben rendir cuentas principalmente a la audiencia, y a la ciudadanía en general, así como respetar su propia conciencia, las normas éticas y los valores democráticos. Sin embargo, reconocen que, en lugar de esto, se anteponen los intereses políticos. Según la ciudadanía, actualmente, los medios dan explicaciones al gobierno, los partidos políticos o los anunciantes, antes que a la ciudadanía, un hecho que genera rechazo entre los participantes de los grupos de discusión.

En este ámbito, defienden la necesidad de un comportamiento respetuoso mutuo entre periodistas y políticos. Los partidos deberían respetar las diferencias ideológicas de los periodistas y su necesidad de acceso a la información, aseguran los participantes. En este contexto, las posibles prebendas o regalos que los políticos ofrecen a los periodistas serían otro aspecto a vigilar. Aceptar la invitación para asistir a conferencias u otras actividades organizadas por partidos puede suponer vincularse con una opción política y convertirse en una situación incómoda para el periodista que quiere conservar su imagen de independencia. Frente a las injerencias del poder político, la ciudadanía propone que existan organismos públicos de control, con autoridad para sancionar y mantener la independencia respecto de estamentos políticos. No obstante, se muestran pesimistas sobre la implantación real de organismos de este tipo: "Debería haber un organismo que estuviera vigilando si la ética de los medios de comunicación es acorde con lo que supone el valor supremo de la información en la vida de los ciudadanos" (hombre, focus group n $\mathrm{n}^{\mathbf{0}}$ ).

En general, se detecta cierta sensación de desamparo respecto a las opciones de regulación de la profesión periodística. La ciudadanía no encuentra opciones óptimas para regular a los medios, ni siquiera desde los organismos públicos, porque están muy influenciados políticamente, según dicen. Afirman que actualmente es fácil encontrar abusos y conductas poco éticas, como evadir información cuando se cuestiona jurídicamente la actuación de un gobernante, denuncias de periodistas tras recibir coacciones de los directivos de su medio o preguntas prohibidas que los periodistas no pueden formular a un alto cargo público, entre otros ejemplos. Según uno de los participantes, sería necesario un cambio en la mentalidad de la gente para anteponer la ética al dinero y al poder.

\section{Discusión y conclusiones}

La existencia de presiones políticas en el periodismo es un hecho que se remonta a los inicios de la propia profesión (Aznar, 1999; Bertrand, 2000; Hallin y Mancini, 2004; Weaver y Wilhoit, 1986). Una situación que, no por esperable, deja de preocupar a periodistas y ciudadanos, como demuestran los resultados expuestos en este artículo.

Son distintos los factores que propician esta situación de injerencia de la política en el periodismo, según detectan los propios periodistas y los ciudadanos. Estos factores, a su vez, entrañan un contexto de debilidad en el periodismo que facilita la irrupción de dichas injerencias. La politización 
de los medios y de la línea editorial, la crisis económica y de modelo de negocio, la precariedad laboral o la falta de cultura democrática de la clase política son algunas de las cuestiones que periodistas y ciudadanos señalan como elementos que influyen negativamente en la profesión periodística. Esto se debe, según los periodistas y ciudadanos, a la relación de dependencia que se establece entre los periodistas y el poder político, una tendencia ampliamente constatada por la literatura (Almirón, Narberhaus y Mauri, 2016; Casero y López, 2016) que, según los resultados, se afianza en lugar de remitir, en línea con los hallazgos de investigaciones recientes (Graber y Dunaway, 2017; McNair, 2018).

Es coherente con esta visión el hecho de que la politización de los medios de comunicación o las presiones políticas y gubernamentales sean algunos de los supuestos que más afectan a la situación del periodismo en España, según los periodistas encuestados. Los resultados obtenidos en esta investigación son también coherentes con el "Informe anual de la profesión periodística", una monitorización del estado de la profesión que desde la Asociación de la Prensa de Madrid se realiza cada año. La encuesta correspondiente al año 2017, con una muestra de 1756 personas que trabajan en el ámbito de la comunicación, revela que la falta de independencia política o económica es el tercer problema más importante de la profesión, con un 14,7\%, solo por detrás del aumento del paro y la precariedad laboral y la mala retribución del trabajo periodístico. En una escala del 0 al 10 (donde 0 es nada de independencia y 10 es independencia total), los periodistas encuestados sitúan su nivel de libertad en un 4,4, por debajo del aprobado. Finalmente, y según la misma encuesta, el $80 \%$ de los periodistas confiesan haber recibido presiones a la hora de ejercer su función profesional.

Todos estos factores no facilitan, más bien frenan el desarrollo de instrumentos de rendición de cuentas del periodismo ante el público, porque limitan la autorregulación periodística en la medida en que condicionan la libertad de prensa; dificultan la existencia de unos medios de comunicación transparentes; y no contribuyen a la participación del público, elementos clave para poder hablar de rendición de cuentas (Mauri y Ramon, 2015). En consecuencia, se observa que las injerencias políticas y las presiones gubernamentales son un obstáculo a la voluntad de crear instrumentos de rendición de cuentas de los medios de comunicación (Rodríguez, López, Merino y Mauri, 2017). Los ciudadanos coinciden con los periodistas en este punto. Desconfían de los medios a causa de una influencia política que, según apuntan, afecta a la objetividad e independencia periodística (Kovach y Rosenstiel, 2001), lo que pone en peligro la función democratizadora de los medios en sociedades libres (Alsius, 2010; Casero-Ripollés, 2012).

Pese a la situación descrita por todos los actores que participan del sistema de medios (periodistas y ciudadanía), es relevante señalar que estas presiones y la precariedad laboral -que agudiza una situación de debilidad profesional que favorece todo tipo de injerencias- no consiguen doblegar a la mayoría de periodistas en alguna cuestión concreta. Así, según revela la encuesta, los periodistas españoles no ceden a presiones cuando algunos políticos o cargos de gobierno quieren ser entrevistados por propia voluntad y no por interés periodístico. Por lo tanto, se concluye que los periodistas reconocen las presiones políticas y gubernamentales, pero no ceden ante ellas ni se sienten responsables ante partidos o gobiernos. Al respecto, las normas éticas, las propias fuentes y, ante todo, la propia conciencia, marcan el sentido de responsabilidad de los periodistas españoles.

\section{Referencias}

Almiron, N., Narberhaus, M., \& Mauri, M. (2016). Mapping media accountability in stateless nations: The case of Catalonia. Catalan journal of communication \& cultural studies, 8(2), 207225. https://doi.org/10.1386/cjcs.8.2.207_1 
RLCS, Revista Latina de Comunicación Social, 77, 295-308

[Investigación] DOI: 10.4185/RLCS-2020-1459 | ISSN 1138-5820 | Año 2020

Alsius, S y Salgado, F. (Eds.). (2010). La ética informativa vista por los ciudadanos. Editorial UOC.

Alsius, S. (1999). Codis ètics del periodisme televisiu. Pòrtic.

Alsius, S. (Ed.). (2010). The ethical values of journalists: field research among media professionals in Catalonia. Generalitat de Catalunya.

Asociación de la Prensa de Madrid (2017). Informe Anual de la Profesión Periodística, 2017. APM.

Aznar, H. (1999). Ética y periodismo: autorregulación, códigos, estatutos de redacción y otros documentos. Paidós.

Bertrand, C. J. (2000). Media ethics and accountability systems. Routledge.

Casero-Ripollés, A., \& López-Rabadán, P. (2016). Periodistas y políticos en España. Editorial UOC.

Casero-Ripollés, A. (2012). El periodismo político en España: algunas características definitorias. En VV.AA, Periodismo político en España: concepciones, tensiones y elecciones (pp. 19-46). Sociedad Latina de Comunicación Social.

Eberwein, T., Fengler, S., Philipp, S., \& Ille, M. (2014). Counting media accountability-The concept and methodology of the MediaAcT survey, en Fengler, S.; Eberwein, T.; Mazzoleni, g.; Porlezza, C.; Russ-Mohl (Eds.), Journalists and Media Accountability: An International Study of News People in the Digital Age (pp. 65-79). Peter Lang.

Fengler, S., \& Ruß-Mohl, S. (2008). Journalists and the information-attention markets: Towards an economic theory of journalism. Journalism, 9(6), 667-690.

https://doi.org/10.1177/1464884908096240

Fengler, S., et al. (2015). How effective is media self-regulation? Results from a comparative survey on European journalists. European Journal of Communication, 30(3), 249-266.

Frost, C. (2015). Journalism ethics and regulation. Routledge.

Fuentes, J. C. P. (Ed.). (2004). Ética periodística: Principios, códigos deontológicos y normas complementarias. Servicio Editorial de la Universidad del País Vasco.

Graber, D. A., \& Dunaway, J. (2017). Mass media and American politics. Cq Press.

Green-Pedersen, C., \& Stubager, R. (2010). The Political Conditionality of Mass Media Influence: When Do Parties Follow Mass Media Attention?. British Journal of Political Science, 40(3), $663-$ 677. https://doi.org/10.1017/S0007123410000037

Guillamet, J. (2003). Història del periodisme: notícies, periodistes i mitjans de comunicació (Vol. 14). Universitat de Barcelona.

Hallin, D. C.; \& Mancini, P. (2004). Comparing media systems: Three models of media and politics. Cambridge University Press. 
RLCS, Revista Latina de Comunicación Social, 77, 295-308

[Investigación] DOI: 10.4185/RLCS-2020-1459 | ISSN 1138-5820 | Año 2020

Hardy, J. (2008). Western media systems. Routledge. https://doi.org/10.1177/0267323114561009

Kovach, B., \& Rosenstiel, T. (2001). Are watchdogs an endangered species? Columbia Journalism Review, 40(1), 50-50.

Maheshwari, S., \& Sparks, C. (2018). Political elites and journalistic practices in India: A case of institutionalized heteronomy. Journalism, 1464884918761630.

https://doi.org/10.1177/1464884918761630

Mauri-Ríos, M. \& Ramon-Vegas, X. (2015). Nuevos sistemas de rendición de cuentas de la información periodística: exploración del escenario online español. El profesional de la información, 24(4), 380-389. https://doi.org/10.3145/epi.2015.jul.04

Mauri-Ríos, M.; Marcos-García, S., \& Zuberogoitia-Espilla, A. (2020). Analysis of professional perceptions relating to the effectiveness of codes of ethics for journalists in Spain. Journal of information, communication and ethics in society, 1-18. https://doi.org/10.1108/JICES-11-2019$\underline{0123}$

Mazzoleni, G., \& Schulz, W. (1999). "Mediatization" of politics: A challenge for democracy? Political communication, 16(3), 247-261. https://doi.org/10.1080/105846099198613

McNair, B. (2018). An introduction to political communication. Routledge.

Meyer, T. (2002). Media democracy: How the media colonize politics. Polity.

Nordenstreng, K., \& Hannikainen, L. (1984). The mass media declaration of UNESCO. Praeger Pub Text.

Parmelee, J. H. (2013). Political journalists and Twitter: Influences on norms and practices. Journal of Media Practice, 14(4), 291-305. https://doi.org/10.1386/jmpr.14.4.291_1

Rodríguez Martínez, R., López-Meri, A., Merino Arribas, A., y Mauri-Rios, M. (2017). Instrumentos de rendición de cuentas en España. Análisis comparativo en Cataluña, Galicia, Madrid y Valencia. El Profesional de la Información, 26(2), 225-67. https://doi.org/10.3145/epi.2017.mar.12

Rodríguez-Martínez, R.; Figueras, M.; Mauri-Ríos, M, \& Alsius, S. (2013). How dominant are official sources in shaping political news coverage in Spain? The perceptions of journalists and citizens. Journal of mass media ethics, 28(2), 103-118. https://doi.org/10.1080/08900523.2013.792697

Rodríguez-Martínez, R.; Mauri-Ríos, M., \& Fedele, M. (2017). Criticism as an accountability instrument: the opinión of Spanish journalists. Communication \& Society, 30(1), 57-72. https://doi.org/10.15581/003.30.1.57-72

Rosenstiel, T., \& Kovach, B. (2001). The elements of journalism: What newspeople should know and the public should expect. Crown publishers.

Sjøvaag, H. (2020). Journalistic autonomy: Between structure, agency and institution. Nordicom review, 34(s1), 155-166. https://doi.org/10.2478/nor-2013-0111 
Strömbäck, J. (2011). Mediatization and perceptions of the media's political influence. Journalism studies, 12(4), 423-439. https://doi.org/10.1080/1461670X.2010.523583

Suárez-Villegas, J. C., Rodríguez-Martínez, R., Mauri-Ríos, M. y López-Meri, A. (2017). Accountability y culturas periodísticas en España. Impacto y propuesta de buenas prácticas en los medios de comunicación españoles (MediaACES). Revista Latina de Comunicación Social, (72), 321-330. https://doi.org/10.4185/RLCS-2017-1167

Tandoc Jr., E. C. (2018). Gatekeeping Influences and Journalistic Capital: Proposing a mechanism of influence. Journalism Studies, 19(16), 2344-2358. https://doi.org/10.1080/1461670X.2017.1345320

Van Dalen, A. (2012). The people behind the political headlines: A comparison of political journalists in Denmark, Germany, the United Kingdom and Spain. International Communication Gazette, 74(5), 464-483. https://doi.org/10.1177/1748048512445154

Weaver, D. H., Wilhoit, G. C., \& Bergen, L. A. (1991). The American journalist: A portrait of US news people and their work. Indiana University Press.

Weischenberg, S.; Malik, M.; \& Scholl, A. (2006). Journalismus in Deutschland 2005. Media Perspektiven, (7), 346-361.

Wimmer, R. D.; \& Dominick, J. R. (2011). Mass media research: an introduction (novena edición). Wadsworth, Cengage Learning.

\section{AUTORES:}

\section{Marcel Mauri-Rios}

Doctor en Periodismo. Es historiador, periodista y profesor de Historia del periodismo y la ética periodística en el Departamento de Comunicación de la UPF. También es consultor de la ética y el derecho de comunicación en la Universitat Oberta de Catalunya (UOC). En 2007 llevó a cabo una estancia predoctoral en la Universidad de la Sorbona en París y en 2010 realizó una estancia postdoctoral en la Universidad de Columbia (Nueva York). Ha publicado sobre la ética de los medios e Historia del Periodismo.

marcel.mauri@upf.edu

Índice H: 10.

Orcid ID: https://orcid.org/0000-0003-2615-8343

Google Scholar: https://scholar.google.com/citations?user=H2SFG0kAAAAJ\&hl=en

\section{Amparo López-Meri}

Profesora en Periodismo y Comunicación Audiovisual en la Universitat Jaume I de Castellón, en España. Sus actuales líneas de investigación tratan la reformulación del periodismo en el entorno digital y el impacto de los medios sociales en el periodismo y la comunicación política. Forma parte del grupo de investigación Periodismo, Comunicación, Poder de la Universitat Jaume I. Además, tiene una larga trayectoria en los medios de comunicación como reportera de la agencia de noticias Europa Press TV y editora de informativos en diferentes canales de televisión españoles.

meri@uji.edu

Índice H: 11.

Orcid ID: https://orcid.org/0000-0003-3408-2190

Google Scholar: https://scholar.google.es/citations?user=PGmmpFAAAAAJ\&hl=ca 


\section{Cristina Perales-García}

Doctora en Periodismo y Ciencias de la Comunicación por la Universidad Autónoma de Barcelona. Es profesora de Periodismo en el Departamento de Comunicación de la Universitat Pompeu Fabra y miembro del Grupo de Investigación en Periodismo (GRP) de la misma universidad. Ha participado en proyectos de investigación financiados por el Ministerio y organismos públicos. Sus principales líneas de investigación son la ética en los medios, historia del periodismo, comunicación política y estudio de los discursos periodísticos. Ha realizado diversas estancias de investigación en universidades europeas, entre ellas destaca la realizada en la University of Stirling (Stirling, Escocia), la University of Applied Sciences (Tampere, Finlandia) y la Université de Poitiers (Poitiers, Francia).

cristina.perales@upf.edu

\section{Índice H: 7.}

Orcid ID: https://orcid.org/0000-0003-2937-2468

Google Scholar: https://scholar.google.es/citations?user=M4sm_y8AAAAJ\&hl=ca 